\title{
Comparison between Synthetic Inertia and Fast Frequency Containment Control Based on Single Phase EVs in a Microgrid
}

Rezkalla, Michel M.N.; Zecchino, Antonio; Martinenas, Sergejus; Prostejovsky, Alexander; Marinelli, Mattia

Published in:

Applied Energy

Link to article, DOI:

10.1016/j.apenergy.2017.06.051

Publication date:

2017

Document Version

Peer reviewed version

Link back to DTU Orbit

Citation (APA):

Rezkalla, M. M. N., Zecchino, A., Martinenas, S., Prostejovsky, A., \& Marinelli, M. (2017). Comparison between Synthetic Inertia and Fast Frequency Containment Control Based on Single Phase EVs in a Microgrid. Applied Energy, 210, 764-775. https://doi.org/10.1016/j.apenergy.2017.06.051

\section{General rights}

Copyright and moral rights for the publications made accessible in the public portal are retained by the authors and/or other copyright owners and it is a condition of accessing publications that users recognise and abide by the legal requirements associated with these rights.

- Users may download and print one copy of any publication from the public portal for the purpose of private study or research.

- You may not further distribute the material or use it for any profit-making activity or commercial gain

- You may freely distribute the URL identifying the publication in the public portal 


\title{
Comparison between Synthetic Inertia and Fast Frequency Containment Control Based on Single Phase EVs in a Microgrid
}

\author{
Michel Rezkalla ${ }^{\mathrm{a}}$, Antonio Zecchino ${ }^{\mathrm{a}}$, Sergejus Martinenas ${ }^{\mathrm{a}}$, Alexander M. Prostejovsky ${ }^{\mathrm{a}}$, \\ Mattia Marinelli ${ }^{\mathrm{a}, *}$ \\ ${ }^{a}$ Center for Electric Power and Energy, Department of Electrical Engineering, \\ Technical University of Denmark
}

\begin{abstract}
The increasing share of distributed and inertia-less resources entails an upsurge in balancing and system stabilisation services. In particular, the displacement of conventional generation reduces the available rotational inertia in the power system, leading to high interest in synthetic inertia solutions. The objective of this paper is twofold: first, it aims to implement and validate fast frequency control and synthetic (virtual) inertia control, employing single phase electric vehicles as flexibility resources. Second, it proposes a trade-off analysis between the two controllers. The interdependency between frequency containment and synthetic inertia control on the transient frequency variation is shown analytically. The capabilities and limits of series produced EVs in providing such services are investigated, first on a simulation based approach and subsequently by using real hardware. The results show that fast frequency control can improve the transient frequency behaviour. However, both on the simulation and on the experimental level, the implementation of synthetic inertia control is more challenging. In fact, due its derivative nature and the system dynamics, its performance is limited. Furthermore, the crucial importance of the EVs' response time for both controllers is highlighted.
\end{abstract}

Keywords: electric vehicles, experimental validation, frequency containment control, frequency stability, synthetic inertia.

\footnotetext{
${ }^{*}$ Corresponding author

Email address: matm@elektro.dtu.dk (Mattia Marinelli) 


\section{Nomenclature}

$\bar{T}_{D} \quad$ Frequency dependent loads

$\bar{T}_{F C C}$ Electric torque of devices participating in FCC

$\bar{T}_{S I C}$ Electric torque of devices participating in SIC

$\delta \quad$ Electrical rotor angle

$\delta_{0} \quad$ Rotor angle at $\mathrm{t}=0$

$\omega_{e} \quad$ Angular velocity of the electrical rotor

$\omega_{m} \quad$ angular velocity

$\omega_{0 m} \quad$ Rated angular velocity

$f \quad$ Frequency

$H \quad$ Kinetic energy in Watt-per-seconds at rated speed

I $\quad$ EV absorbed Current

$J \quad$ Moment of inertia

$K_{D} \quad$ Load damping factor

$K_{F C C}$ FCC proportional control coefficient

$K_{\text {SIC }}$ SIC proportional control coefficient

$P \quad$ EV absorbed active power

$p \quad$ Number of pole pairs

$S_{b} \quad$ Generator's rated power 


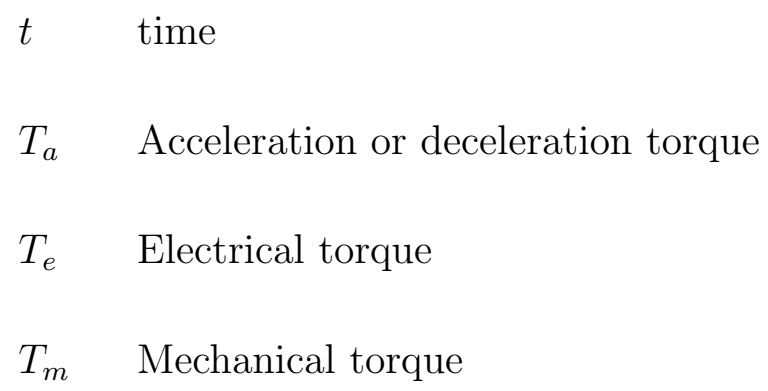

\section{Introduction}

The rising share of inverter-coupled distributed energy resources (DER) raises new challenges in maintaining stable grid operation. One of the main issues is the reduction of the system inertia due to the replacement of rotating generators by converter-connected resources, as well as the expansion of high-voltage direct current (HVDC) connections, which decouples the inertial response between the interconnected areas [1]. Thus, the system's ability to withstand frequency changes by releasing or absorbing the energy stored in the rotating masses is notably reduced, leading to faster frequency dynamics [2]. Moreover, the high volatility of renewable energy sources (RES) contributes to the frequency stability issue by changing the grid inertia over time and increasing the need for better planning due to higher uncertainty.

Inertia is the parameter that represents the capability of rotating machines (including loads, when applicable) to store and inject their kinetic energy into the system [3]. The amount of inertia influences the frequency gradient, which is generally addressed as the rate of change of frequency ( $\mathrm{RoCoF})$ and the transient frequency values during a system incident. The RoCoF and the transient frequency values have a fundamental role in maintaining and operating the power system in a secure state. A large RoCoF and/or transient frequency deviations can lead to the automatic tripping of conventional generators and DER units [4] because they are connected to the grid by means of RoCoF or frequency relays [3]. The RoCoF relay limit is established by the grid code, which varies among countries. 
Several transmission system operators (TSOs) have started to address this challenge, recognising the potential value of the inertial response of wind power plants, synchronous condensers, and synthetic inertia [5, 6]. One of the main concerns of TSOs is the RoCoF, which might lead to a cascade tripping of conventional and DER units connected by means of RoCoF relays [4, 7]. According to [8], an RoCoF relay has a typical delay in the range of $50 \mathrm{~ms}$ to $500 \mathrm{~ms}$.

Further, the growing number of electric vehicles $(\mathrm{EVs})$ has concerned distribution system operators (DSOs). The uncertainty of EV driving patterns, high penetration levels and charging in the distribution network could result in new system peaks and negative distribution system impacts, exceeding the load capacities of distribution lines and transformers [9, 10].

The effects of EVs on future power systems are investigated in several studies, such as in [11, 12]. In [11], the negative effects of uncoordinated charging of EVs on the power system was addressed. The authors presented the impacts that EV charging can have in an actual working wholesale electricity market. In [12] it was analysed how a large scale implementation of plug-in hybrid electric vehicles and full electric vehicles would influence the power system. This study shows that smart management of EVs bidirectional charging can alleviate peak power demand.

On the other hand, unscheduled high penetration of EVs may have detrimental effects on power system performance. Reliability and stability are the aspects of the grid that face the most challenges when EVs are used widely. Consequently, there is an exigent need to predict the EVs' customers in order to avoid irreparable effects, especially for the distribution network. Several studies have investigated these challenges, such as as in [13, 14]. In [13] the authors propose a simultaneous approach for allocation of EV parking lots and DRRs in a power distribution network to achieve a more reliable supply of the load demand. A probabilistic modelling of EVs' charging demand is presented in [14].

A noticeable amount of research has focused on the transition from the traditional system, where frequency is controlled by a small set of large generating units, to the future where it is controlled by a vast amount of small distributed resources [15, 16]. 
Given that EVs are essentially battery storages with a seconds-range response time, the TSO can greatly benefit from EV participation in frequency service provision. As analysed in [17], EV participation in the ancillary service market appears to be one of the most promising applications because it can offer substantial earnings to EV aggregators and EV owners. Ref. [18] concluded that although V2G capable EVs can provide great benefits to the ancillary service market, battery degradation may represent a challenge for their viability [19, 20].

EVs are able to provide fast regulating power bidirectionally using Vehicle-to-Grid or just by modulating the charging power unidirectionally [21, 22]. In this context, EVs can play a fundamental role in the future ancillary service market. Although the potential benefits of exploiting the V2G capability for ancillary services was introduced in [23], this study did not investigate uni-direction EVs charging in providing such services.

Due to the reduced system inertia, various studies have shown the techno-economic benefits and challenges of primary frequency provision from EVs, such as in [24 26]. In [24] the authors present the impact of declining system inertia on the primary frequency control (PFC) and future requirements. It also presents the impact of PFC provision from EVs on the system frequency performance. In [25] the authors present the general ability of EV fleets to utilize fluctuating renewable energy sources for charging and their effects on the power system. The authors in [26] summarise the challenges to control a system with low inertia. In this study, unlike in [11, 12, 23], EVs have been controlled by only modulating the charging current between 6 and 16A with steps of 1 A to comply with the technical constraints imposed by the IEC 61851 standard [27, 28].

Simultaneously, very few studies have investigated the EV's ability in providing synthetic inertia services. In [29] the authors presented a single-phase virtual synchronous machine (VSM) and its possible application for providing V2G services from an EV's batteries, this work was supported by an experimental setup that is based on the Opal-RT platform. In contrast, this paper presents a different approach in providing synthetic inertia services supported by an experimental investigation using series produced EVs.

The scope of this study is twofold: First, the EV's capabilities as flexibility resources are 
investigated. In particular, this study looks at synthetic inertia control (SIC) and frequency containment control (FCC) as exemplary services. Second, it analyses and evaluates the pros and cons of SIC and FCC on the frequency dynamics (e.g. RoCoF and frequency nadir and zenith). The general objective is to determine if SIC and FCC delivered by converter connected resources, which are relatively fast compared to conventional units, can replace or at least reduce the need for a conventional inertial response.

Ultimately, the research question that this study addresses is: given the trend of decreasing system inertia, can fast frequency containment compensate or replace the need for synthetic inertia?

The method and the results presented in this study are part of the EU-funded project ELECTRA IRP, which proposes novel frequency and voltage control concepts to maintain and operate the power system in a secure state [30]. It considers the grid inertia (i.e. the synchronous and synthetic inertia) to be an active part of the frequency control process and it is addressed by inertia response power control (IRPC). In this study, the synthetic inertia is considered to be an active part of the IRPC process.

This paper is divided into the following five sections: Section 2 presents the frequency control in Europe and the analytical interdependency between frequency containment and synthetic inertia. Section 3 presents the frequency containment and the synthetic inertia controllers, the EV dynamic model and the experimental layout. The simulations and experimental results are shown and discussed in section 4. Lastly, section 5 presents the conclusions and it outlines future research points.

\section{Frequency Control in Europe and Analytical Formulation}

This section presents a summary of the current framework for frequency control in Europe and it gives an overview of synthetic inertia and frequency assessment.

\subsection{Framework for Frequency Control in Europe}

Based on the network code that was defined by the European Network of Transmission System Operators for Electricity (ENTSO-E), frequency control is divided into the following 
three phases: (i) Primary frequency control, (ii) Secondary power-frequency control, and (iii) Tertiary control. ENTSO-E refers to the reserves for frequency control as operating reserves, and it specifically indicates the previously mentioned controls, respectively, as: (i) Frequency Containment Reserves (FCR), (ii) Frequency Restoration Reserves (FRR), and (iii) Replacement Reserves (RR).

The frequency containment stabilises the frequency, after a disturbance, at a steady-state value within the permissible maximum steady-state frequency deviation. This is done by a joint action of FCR within the synchronous area [31]. The frequency restoration process controls the frequency towards its set-point value by activation of FRR and it replaces the activated FCR. The reserve replacement process replaces the activated FRR and/or supports the FRR activation by activation of RR. One can notice that the inertial response is considered to be a natural characteristic of the power system.

\subsection{Analytical Interdependency Between Frequency Containment and Synthetic Inertia}

According to IEEE/CIGRE task force, frequency stability is the ability of the power system to maintain steady state frequency following a severe system upset, resulting in a significant imbalance between generation and load [32]. Frequency stability depends on the system's ability to restore the equilibrium between generation and load demand.

During any disturbance that causes an imbalance between the torques acting on the rotor (i.e. active power imbalance between generation and consumption), the net torque causing acceleration or deceleration is $T_{a}=T_{m}-T_{e}$, where $T_{m}$ is the mechanical torque applied on the rotor, $T_{e}$ is the electrical torque on the rotor. The simplest model of electro-mechanical swings in a power system is based on the so called swing equation:

$$
T_{a}=T_{m}-T_{e}=J \frac{d \omega_{m}}{d t}
$$

where $J$ is the combined moment of inertia of the generator and the turbine $\left(\mathrm{kgm}^{2}\right)$, and $\omega_{m}$ is the angular velocity of the rotor $(\mathrm{rad} / \mathrm{s})$.

Following an imbalance between the torques (i.e. imbalance between generation and demand), the kinetic energy stored in the rotating masses of the generator and the prime 
mover is released. The kinetic energy at rated speed is expressed as $E_{k i n}=\frac{1}{2} J \omega_{0 m}^{2}$, where $\omega_{0 m}$ is the rated angular velocity [33]. By normalising the previous equation in terms of the rated power of the generator $S_{b}$, the inertia constant $H$ can be defined as the kinetic energy in Watt-per-seconds at rated speed:

$$
H=\frac{J \omega_{0 m}^{2}}{2 S_{b}} \quad \Longrightarrow \quad J=\frac{2 H S_{b}}{\omega_{0 m}^{2}}
$$

Equation (1) can be reformulated as:

$$
\frac{T_{m}-T_{e}}{S_{b} / \omega_{0 m}}=2 H \frac{\mathrm{d}}{\mathrm{d} t}\left(\frac{\omega_{m}}{\omega_{0 m}}\right)
$$

Since $S_{B} / \omega_{0 m}$ is the base torque $T_{b a s e}$, the (3) can be expressed in p.u. as:

$$
\begin{gathered}
\bar{T}_{m}-\bar{T}_{e}=2 H \frac{\mathrm{d} \bar{\omega}_{r}}{\mathrm{~d} t} \\
\bar{\omega}_{r}=\frac{\omega_{m}}{\omega_{0 m}}=\frac{\omega_{e} / p}{\omega_{0} / p}=\frac{\omega_{e}}{\omega_{0}}=\bar{\omega}_{e}
\end{gathered}
$$

where $\omega_{e}$ is the angular velocity of the electrical rotor, $\omega_{0}$ is the rated one and $p$ is the number of pole pairs.

The previous equations can be reformulated in terms of the electrical rotor angle. Assuming $\delta$ as the electrical rotor angle with respect to a synchronously rotating reference and $\delta_{0}$ is the rotor angle at $\mathrm{t}=0, \delta$ can be formulated as:

$$
\delta=\omega_{e} t-\omega_{0} t+\delta_{0}
$$

Therefore, the first and second derivatives of (6) are:

$$
\begin{aligned}
\frac{\mathrm{d} \delta}{\mathrm{d} t} & =\omega_{e}-\omega_{0}=\Delta \omega_{e} \\
\frac{\mathrm{d}^{2} \delta}{\mathrm{d} t^{2}} & =\frac{\mathrm{d} \omega_{e}}{\mathrm{~d} t}=\omega_{0} \frac{\mathrm{d} \bar{\omega}_{r}}{\mathrm{~d} t}
\end{aligned}
$$

Equation(1) can be reformulated in terms of the rotor angle:

$$
\bar{T}_{m}-\bar{T}_{e}=\frac{2 H}{\omega_{0}} \frac{\mathrm{d}^{2} \delta}{\mathrm{d} t^{2}}
$$


Reformulating (9) in terms of $\bar{\omega}_{e}$ :

$$
\bar{T}_{m}-\bar{T}_{e}=2 H \frac{\mathrm{d} \bar{\omega}_{e}}{\mathrm{~d} t}
$$

Assuming that $\bar{T}_{m}$ is constant and that the frequency regulation is only from the load side, then one can assume that $\bar{T}_{e}$ is composed by: the frequency dependent loads $\left(\bar{T}_{D}\right)$, devices participating in FCC $\left(\bar{T}_{F C C}\right)$ and devices participating in SIC $\left(\bar{T}_{S I C}\right)$ :

$$
\bar{T}_{e}=\bar{T}_{D}+\bar{T}_{F C C}+\bar{T}_{S I C}
$$

where each is composed by a base value and frequency dependent value:

$$
\begin{aligned}
\bar{T}_{D} & =\bar{T}_{D_{0}}+K_{D} \Delta \bar{\omega}_{e} \\
\bar{T}_{F C C} & =\bar{T}_{F C C_{0}}+K_{F C C} \Delta \bar{\omega}_{e} \\
\bar{T}_{S I C} & =\bar{T}_{S I C_{0}}+K_{S I C} \frac{\mathrm{d} \bar{\omega}_{e}}{\mathrm{~d} t}
\end{aligned}
$$

$\bar{T}_{D_{0}}, \bar{T}_{F C C_{0}}$ and $\bar{T}_{S I C_{0}}$ represent the base electric torques in steady state and is addressed further as $\bar{T}_{e_{0}}=\bar{T}_{D_{0}}+\bar{T}_{F C C_{0}}+\bar{T}_{S I C_{0}} . K_{D}$ is a damping factor in pu, which considers the electrical loads which change the active power consumption due to frequency changes. $K_{F C C}=K_{F C C}(t-t 0)$ is the FCC proportional control coefficient. $K_{S I C}=K_{S I C}(t-t 0)$ is the SIC proportional control coefficient. $K_{F C C}$ and $K_{S I C}$ are represented in function of the time to represent the time required from those devices to get activated (i.e. time delay). Therefore, the swing equation can be formulated as:

$$
\bar{T}_{m}-\bar{T}_{e_{0}}=\left(2 H+K_{S I C}\right) \frac{\mathrm{d} \bar{\omega}_{e}}{\mathrm{~d} t}+\left(K_{D}+K_{F C C}\right) \Delta \bar{\omega}_{e}
$$

Equation 15 can be expressed as a function of $\frac{\mathrm{d} \bar{\omega}_{e}}{\mathrm{~d} t}$ and $\Delta \bar{\omega}_{e}$ :

$$
\begin{aligned}
\frac{\mathrm{d} \bar{\omega}_{e}}{\mathrm{~d} t} & =\frac{\bar{T}_{m}-\bar{T}_{e_{0}}-\left(K_{D}+K_{F C C}\right) \Delta \bar{\omega}_{e}}{2 H+K_{S I C}} \\
\Delta \bar{\omega}_{e} & =\frac{\bar{T}_{m}-\bar{T}_{e_{0}}-\left(2 H+K_{S I C}\right) \frac{\mathrm{d} \bar{\omega}_{e}}{\mathrm{~d} t}}{K_{D}+K_{F C C}}
\end{aligned}
$$

From (16), one can notice that FCC and SIC can affect the RoCoF variation during a transient. Meanwhile, (17) shows that the frequency deviation from steady state can be 
affected by introducing SIC and FCC. In this regard, the following investigation aims to assess the effects of the two controllers on frequency and RoCoF, by means of simulations and experimental validation.

\section{Methodology}

In this section, the mathematical formulation and characteristic of the implemented controllers as well as the experimental layout is presented.

\subsection{Frequency Containment Control}

Frequency containment control (FCC) is achieved by a joint action of FCC providing units within the whole synchronous area with respect to the frequency deviation. Generally, it is achieved using droop controllers, so that governors operating in parallel can share the load variation according to their rated power. The droop of the generator represents the ratio of frequency deviation to change in power output. The frequency variation, $\Delta f$, referred to the nominal frequency of the system and is given as a function of the relative power change $\Delta P$ or current change $\Delta I$ reported to the nominal machine power or current, respectively.

$$
\text { a) } \frac{1}{K_{F C C}}=\frac{\Delta f / f_{\text {nom }}}{\Delta P / P_{\text {nom }}} ; \quad \text { b) } \frac{1}{K_{F C C}}=\frac{\Delta f / f_{\text {nom }}}{\Delta I / I_{\text {nom }}}
$$

For example, a $5 \%$ droop $\left(\frac{1}{K_{F C C}}\right)$ means that a $5 \%$ frequency deviation causes $100 \%$ change in valve position or power output.

In this study, EVs are used to provide frequency support in terms of FCC by modulating the EV's charging current. Defining a droop value for loads may not be straightforward because the nominal power may not always be determined unequivocally. To comply with the IEC 61851 standard, the EV's charging current can be modulated with a granularity of $1 \mathrm{~A}$, and in this case between 6 and $16 \mathrm{~A}$. This available range of regulating current of 10 A has been assumed as the EV's $I_{\text {nom }}$ [34]. EV charging is controlled by charging controller with a $8 \%$ frequency-current droop with frequency limits of $48-52 \mathrm{~Hz}$.

The droop is presented in Figure 1 - a, where the dash line represents the ideal droop and the solid line represents the real droop with 1 A granularity. To have an up and down 
regulation capability of $\pm 5 \mathrm{~A}$, the EV's initial current set-point is set at $11 \mathrm{~A}$. Due to the 1 A granularity and the established operating point, the EV's current set-point oscillated between 11 and $12 \mathrm{~A}$. To avoid this oscillation, the droop characteristic was shifted; so that the frequency limits became $48.2-52.2 \mathrm{~Hz}$. The control diagram for the FCC is presented in Figure 2-a. Following various experiments, it was noticed that the EV's current was under-shooting [22]. To compensate for this phenomena, it has been used the ceil function for the different controllers instead of the rounding.

\subsection{Synthetic Inertia Control}

Although no direct coupling from converter connected generators to the grid is made, a large amount of kinetic energy is stored in these units (e.g. kinetic energy stored in a wind turbine's blades and gearbox). Together with different forms of energy storage in other units, this can be used to deliver synthetic inertia. This means that these units could mimic synchronous generators by delivering an active power response that is proportional to the RoCoF [35, 36].

A synthetic inertia controller (SIC) is implemented in this study, the control diagram is presented in Figure 2 b. The RoCoF is measured over $200 \mathrm{~ms}$. This unit controls the EV's charging current as a function of a RoCoF-current droop characteristic. The droop is shown in Figure 1-b, the dashed line represents the ideal droop and the solid line represents the 1 A granularity. The droop is implemented by defining the RoCoF's low and high limits, with zero RoCoF corresponding to $11 \mathrm{~A}$. The deadband of $\pm 0.8 \mathrm{~Hz} / \mathrm{s}$ was introduced during the tuning phase where smaller deadband values have led to frequency oscillation. Therefore, it results in a very limited contribution from the EVs.

\subsection{EV dynamic model}

To successfully integrate EVs into power systems, it is necessary to correctly understand and characterise their dynamic behavior. A detailed model is, therefore, derived considering the EV users' driving requirements, the battery charging and discharging characteristics, the battery dynamics (e.g. time response, ramping time, etc..) and the control/communication delays. 

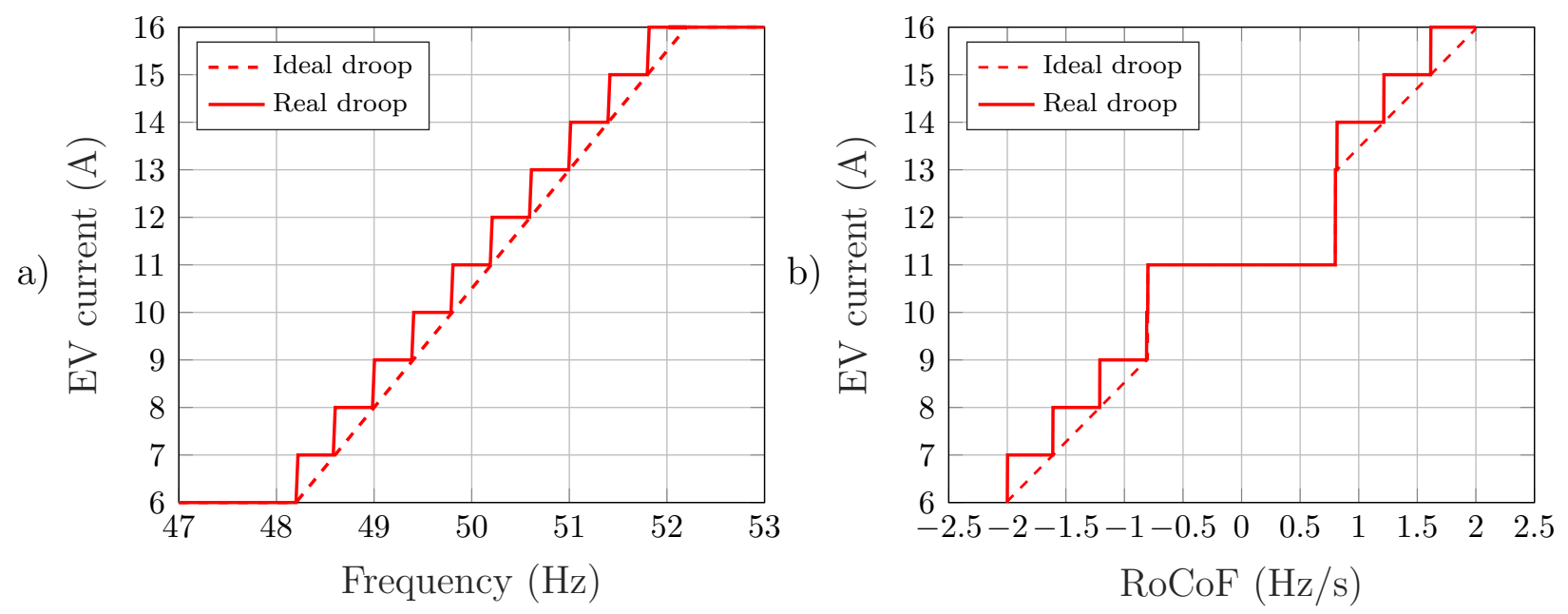

Figure 1: a) FCC droop characteristic, b) SIC droop characteristic

a)
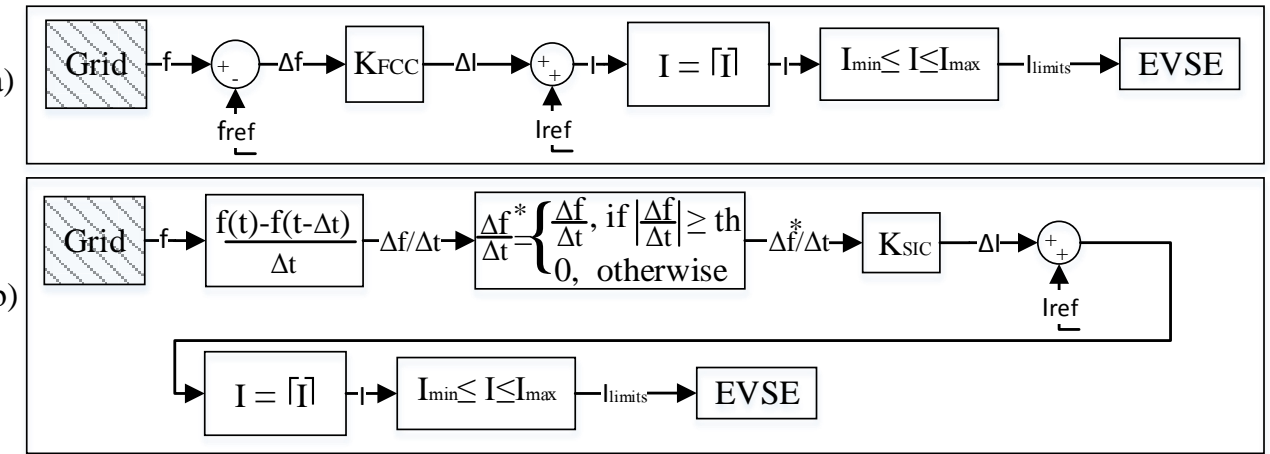

Figure 2: a) FCC control diagram, b) SIC control diagram

Since this study aims to investigate the EV's capabilities and limits in providing fast primary control and synthetic inertia control, the battery charge state was neglected. The EV model is presented in Figure 3. From the dynamic point of view, it is possible to identify two main latencies between the set and the actual current: specifically, a communication delay and the EV activation delay, the sum of which varies between $150 \mathrm{~ms}$ and $2 \mathrm{~s}$. The communication delay depends mainly on latencies in the IT infrastructure, which is in the range of tens of milliseconds. The EV activation delay varies among brands and heavily depends on the embedded power electronics. The most recent models show a faster response time. In any case, the current standard IEC61851 solely requires the car to respond within 
3s. The total delay observed in the experimental trials ranges between 200 and 400ms. Therefore, in the simulation study the total delay is considered to be $250 \mathrm{~ms}$. As a final note with respect to the voltage dependency, the EVs are modelled as constant current loads.

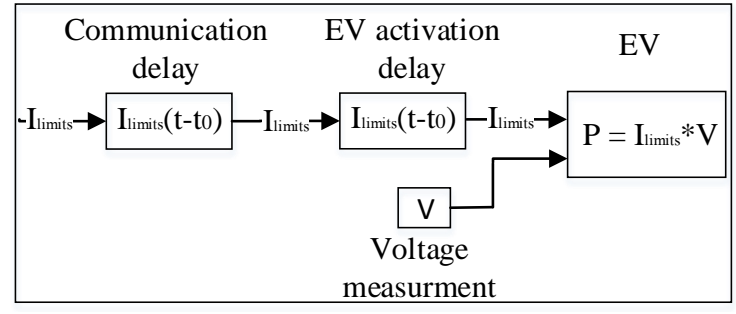

Figure 3: EV dynamic model

\subsection{Experimental Layout and Power Components}

The experiments are executed in the experimental infrastructure SYSLAB, which is part of the PowerLabDK platform. SYSLAB represents a small scale low voltage power system. It consists of a number of real power components that are interconnected by a three-phase $400 \mathrm{~V}$ AC power grid, which is distributed over the Ris $\varnothing$ campus of the Technical University of Denmark [28]. SYSLAB is also characterised by its communication and control nodes, which allow a strong controllability over the grid. The system may be connected to the utility or it can be islanded if desired. The experimental layout is shown in Figure 4.

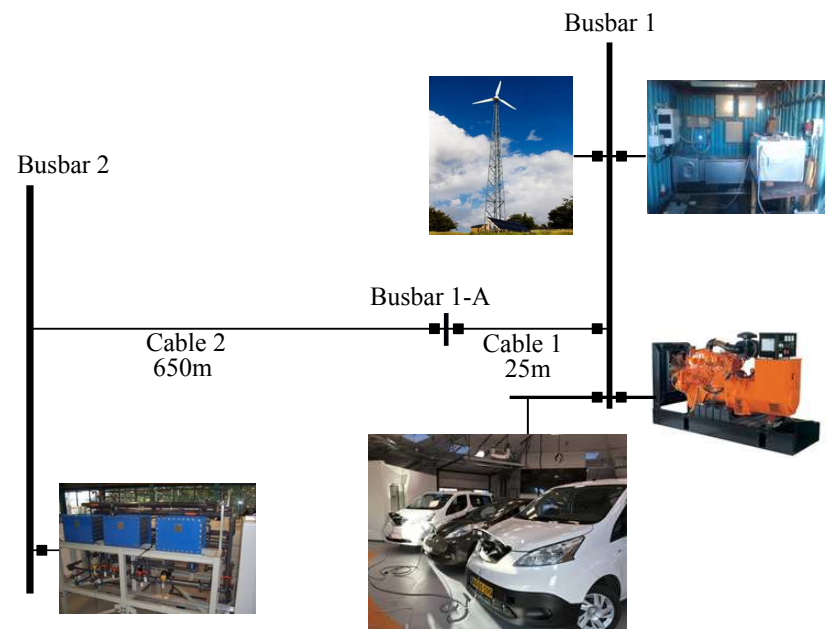

Figure 4: Experimental layout 
The experimental setup is composed by two busbars that are connected by $675 \mathrm{~m}$ underground cable. The VRB is connected to busbar 2 and installed in building 2 where the busbar is located. The rest of the components are connected to busbar 1 and they are installed in the same building as the busbar. The Aircon wind turbine is installed around $10 \mathrm{~m}$ from building 1 . The VRB, the Aircon and the Dump load are controlled through a Matlab/Java interface, while the EVs are controlled through a Python interface. Given that all of the components are 3-phase except the EVs, it has been necessary to create an intermediate phase splitter. Each EV is supplied on a different phase via a standard Mennekes (IEC 62196 Type 2) connector. The three Mennekes plugs are controlled separately by three different pieces of electric vehicle supply equipment (EVSE).

The experiments are executed in an islanded configuration where the diesel generator-set acts as the grid forming unit and is the only synchronous inertia device. It also compensates for the small amount of reactive power drawn by each EV, corresponding to $200 \mathrm{VAr}$ each. The different components used during the experiment are listed in Table 1 where $P 0$ is the base operating point. SC1 and SC2 refer to Study Case 1 and Study Case 2, respectively.

Table 1: Properties of the devices used in the experiments

\begin{tabular}{|c|c|c|c|c|}
\hline Device & Capability & $\begin{array}{c}\mathrm{P} 0(\mathrm{~kW}) \\
\mathrm{SC} 1\end{array}$ & $\begin{array}{l}\mathrm{P} 0(\mathrm{~kW}) \\
\mathrm{SC} 2\end{array}$ & Description \\
\hline Diesel & $\begin{array}{c}0-48 \mathrm{~kW} \\
-20-30 \mathrm{kVAr}\end{array}$ & 24 & 24 & $\begin{array}{l}\text { IVECO genset } \\
\mathrm{S}=60 \mathrm{kVA}, 2 \text { pole pairs }\end{array}$ \\
\hline Aircon & $10 \mathrm{~kW} @ 11 \mathrm{~ms}$ & - & $\sim 4$ & Wind turbine type 4 \\
\hline Battery & $\begin{array}{l} \pm 15 \mathrm{~kW} \\
\pm 12 \mathrm{kVA}\end{array}$ & 9 & - & $\begin{array}{l}\text { Vanadium redox battery, } \\
120 \mathrm{kWh}\end{array}$ \\
\hline Dumpload & $0-78 \mathrm{~kW}$ & 7 & 21 & Resistor load bank \\
\hline EV1 & $\begin{array}{c}6-16 \mathrm{~A} \\
(1.4-3.7 \mathrm{~kW})\end{array}$ & 2.5 & 2.5 & $\begin{array}{l}\text { Nissan leaf } 2016 \text {, } \\
30 \text { kWh lithium battery }\end{array}$ \\
\hline EV2 & $\begin{array}{c}6-16 \mathrm{~A} \\
(1.4-3.7 \mathrm{~kW})\end{array}$ & 2.5 & 2.5 & $\begin{array}{l}\text { Nissan e-NV200 2014, } \\
24 \text { kWh lithium battery }\end{array}$ \\
\hline EV3 & $\begin{array}{c}6-16 \mathrm{~A} \\
(1.4-3.7 \mathrm{~kW})\end{array}$ & 2.5 & 2.5 & $\begin{array}{l}\text { Nissan e-NV200 } 2015, \\
24 \text { kWh lithium battery }\end{array}$ \\
\hline
\end{tabular}




\subsection{EV Charging Controller and Communication Architecture}

Each of the 3 single phase EVs is connected to a different phase of the grid by means of three EVSE. The control and communication setup is shown in Figure 5.

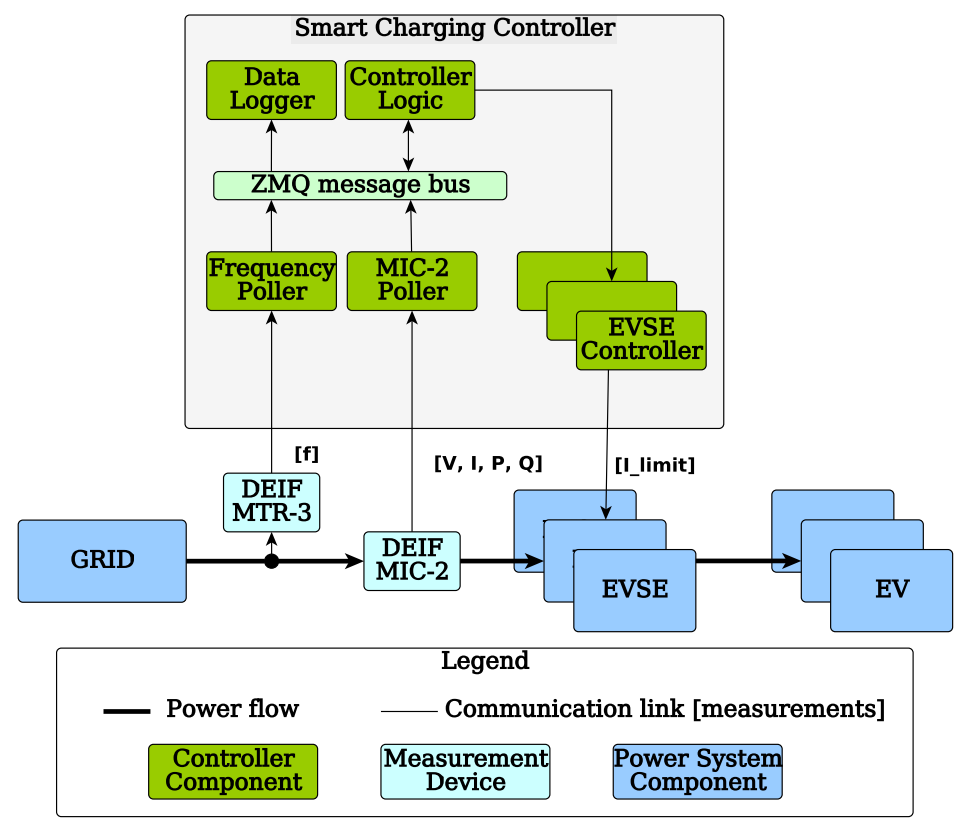

Figure 5: The communication architecture for the implemented smart charging controller

This consists of the following components:

- The smart charging controller - receives the measurements from the multi-instrument, it calculates the response and it sends control signals to the EVSE.

- DEIF MIC-2 - is a multi-instrument measurement device that shows the voltage, current and power measurements with $0.5 \%$ accuracy. The device is only used for data logging.

- DEIF MTR-3 - is a multi-instrument measurement device that is used here for fast frequency measurements, which are polled every $200 \mathrm{~ms}$.

- EVSE - is rated for $16 \mathrm{~A}$

- $\mathrm{EV}$ - is the tested vehicle. 
- Grid - is the grid connection at the SYSLAB experimental facility.

The smart charging controller consists of many sub-components, as follows:

- Controller logic - reads the latest frequency measurements from the message bus and calculates the $\Delta f / \Delta t$ and the $\Delta f$. Calculated set-points are directly sent to the EVSE controller.

- EVSE controller - acts as an interface between the physical EVSE and the controller logic.

- Frequency poller - acts as an interface to the frequency measurement device. In this case DEIF MTR-3 instrument used for frequency sampling every 0.2 seconds with accuracy of $10 \mathrm{mHz}$.

- MIC-2 poller - multi instrument device interface.

- Data logger - monitors the data exchange on the message bus and logs it to the database.

- ZMQ message bus - is the message bus that is used to represent the data exchange between the previously mentioned controller components.

The timing of the response is crucial for the provision of synthetic inertia. Therefore, the timing of each component in the control loop is important: frequency and RoCoF are measured every $200 \mathrm{~ms}$, the controllers' response is almost instantaneous and communication delay (10-20 ms) to each EV/EVSE pair is optimised by controlling them independently. It uses multi-threading and each EVSE only receives a new control signal if the set-point has changed. Finally, the EV's reaction time is approximately 200-300 ms and, therefore, the whole control and actuator chain has an overall latency equal to 400-500 ms. According to this number, it is expected that the device could positively influence the whole frequency dynamic. 


\section{Results and Discussion}

This section is composed by two subsections, in which the simulations and experimental validation are presented. Two study cases are analysed. In the first study case (SC1), the system is studied involving a set of load steps. An alternate load-increase and load-decrease are applied, so that both over and under frequency dynamics can be analysed. In the second study case (SC2), wind power generation is added to the system. It adds random power fluctuations over the tested period and it allows the possibility of investigating the behaviour of the two controllers and the EVs in a more realistic and challenging situation.

The two study cases are each composed of three scenarios: in the first scenario, the EVs are treated as a constant load; that is, constant current set-point equal to $11 \mathrm{~A}$ (Base scenario). In the second scenario, the EVs participate with a synthetic inertia response; that is, SIC. In the third scenario, the EVs participate with a fast frequency response; that is, FCC. An overview of the different scenarios is given in Table 2. During the simulation, only SC1 was analysed.

Table 2: Study cases overview

\begin{tabular}{|l|c|c|}
\hline & Study Case 1 & Study Case 2 \\
\hline Scenario 1 & Base case & Base case + Wind \\
\hline Scenario 2 & SIC & SIC + Wind \\
\hline Scenario 3 & FCC & FCC + Wind \\
\hline
\end{tabular}

\subsection{Simulations}

In this section a simulation study in DigSilent PowerFactory is carried out. It aims to investigate the effects of synthetic inertia control and frequency containment control, and it aims to achieve preliminary results before experimentally validating the controllers. To explore the effects of the 1 A granularity that is imposed by the standard, a sensitivity analysis of different granularity values is conducted.

The same components and grid configuration that are presented in Figure 4 have been modelled, with the operating conditions of SC1, as shown in Table 1 . 
To make this study as realistic as possible, an oscillatory frequency has been induced in the system by means of a fictitious zero-mean variable load by means of fluctuating active power absorbed by the three-phase resistive load. In this way, it has been possible to emulate the realistic frequency oscillation that the real diesel synchronous generator would generate in such an islanded grid configuration.

First, a load event with amplitude of $2 \mathrm{~kW}$ (8.7\% of the total consumption) is applied at $t=10 \mathrm{~s}$ and three scenarios are analysed. The first scenario is considered as a base case where the EVs are treated as a constant load; that is, constant current set-point equal to 11 A. In the second scenario, the EVs participate with a SIC. In the third scenario, the EVs are equipped with the FCC controller. Both the SIC and FCC controllers are implemented according to the control diagrams in Figure 2, thus applying integer EV current set-points to assure standard-compliance. Figure 6 shows the grid frequency, the RoCoF and the EVs' current set-point.

a)

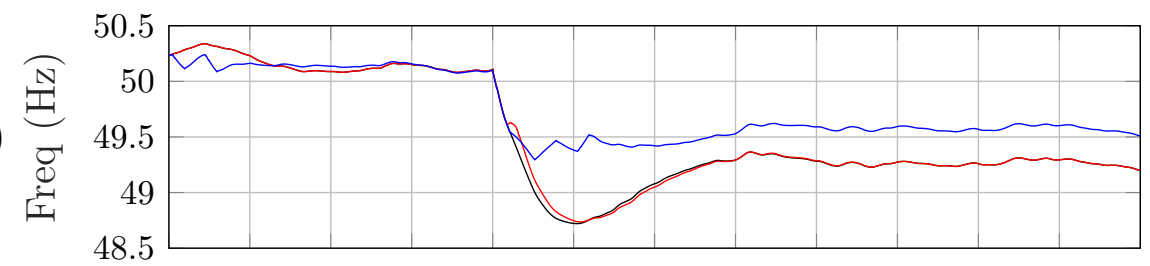

b)

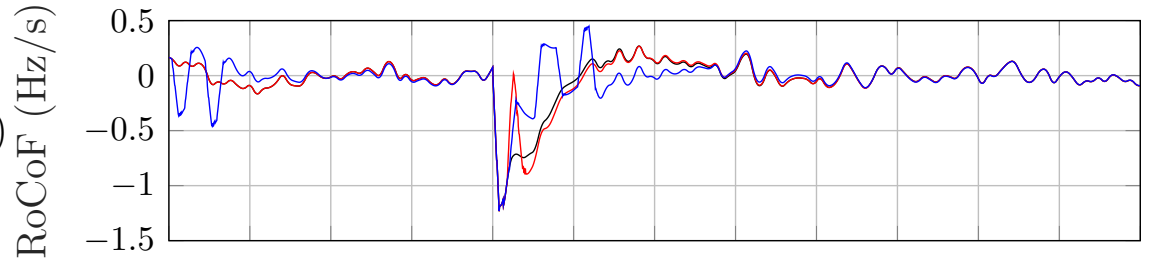

c)

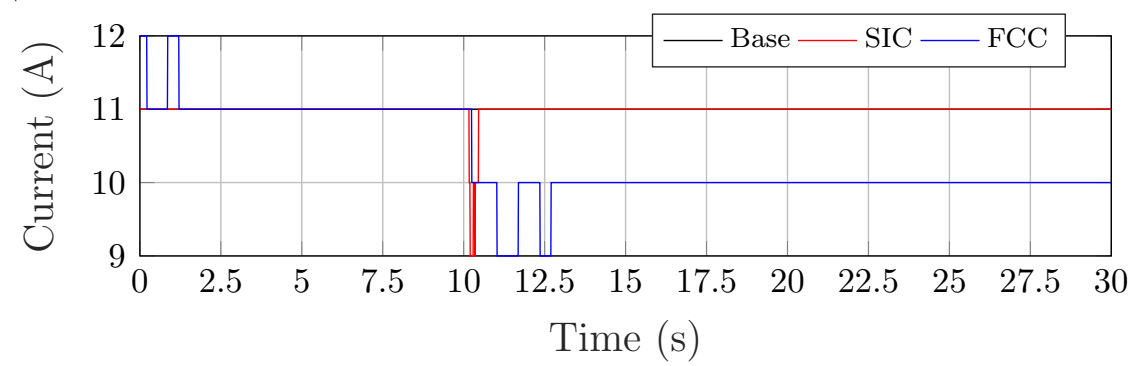

Figure 6: Simulation results obtained by applying $\pm 0.8 \mathrm{~Hz} / \mathrm{s}$ deadband for SIC: a) Frequency, b) RoCoF and c) EV current set-points for the three analysed scenarios, in case of granularity of $1 \mathrm{~A}$. 
As expected, Figure 6-a shows that FCC improves the frequency behaviour in terms of frequency nadir and steady state value. It also shows that SIC ameliorates the frequency slope, which is a typical behaviour of introducing more synchronous and/or synthetic inertia into the system. On the other hand, unexpectedly, Figure 6rb shows that FCC has a better performance in terms of RoCoF compared to SIC.

However, a steeper droop and/or smaller deadband for SIC would have led to better performance regarding the RoCoF and the frequency slope. To demonstrate this point, the same simulations were executed changing the deadband of SIC to $\pm 0.5 \mathrm{~Hz}$ instead of \pm 0.8 Hz. The results are presented in Figure 7.

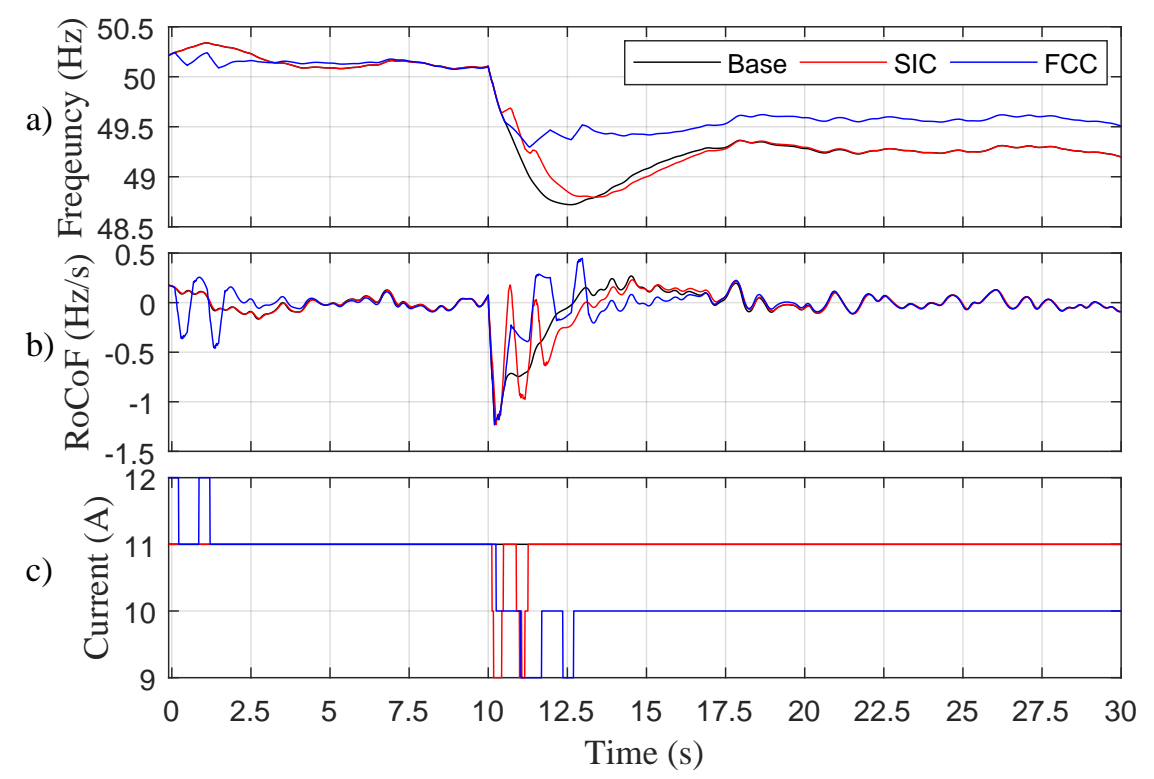

Figure 7: Simulation results obtained by applying $\pm 0.5 \mathrm{~Hz} / \mathrm{s}$ deadband for SIC: a) Frequency, b) RoCoF and c) EV current set-points for the three analysed scenarios, in case of granularity of $1 \mathrm{~A}$.

Figure 7-a shows an improvement regarding the frequency slope compared to the previous case. On the other hand, Figure 7. b shows a marginal improvement regarding the RoCoF. Compared to the previous scenario, Figure $7 \mathrm{fc}$ shows that the EVs were participating more by changing the current set-point.

A sensitivity analysis is performed to better understand the effects of the 1 A granularity imposed by the standard IEC 61851 [27] on the performance of the two controllers. A series 
of simulations are carried out employing different load steps and different granularities. Frequency drops have been obtained by increasing the active power absorbed by the VRB by $20 \%, 40 \%$, and $60 \%$. They represent a load event of $8.7 \%, 15.7 \%$ and $23.5 \%$ of the total consumption, respectively. For the evaluation of the influence of the granularity, the following values of granularity have been applied, which are expressed as fraction of the actual granularity of $1 \mathrm{~A}: \frac{1}{4}, \frac{1}{2}$ and 1 . Moreover, for the sake of completeness, the case of continuous regulation (no granularity) and the uncontrolled case have also been included in the analysis.

Figure 8 reports 3D bar plots of the results for all of the performed simulations. The results are reported by means of standard deviations (SD) for both Frequency and RoCoF for FCC and SIC.
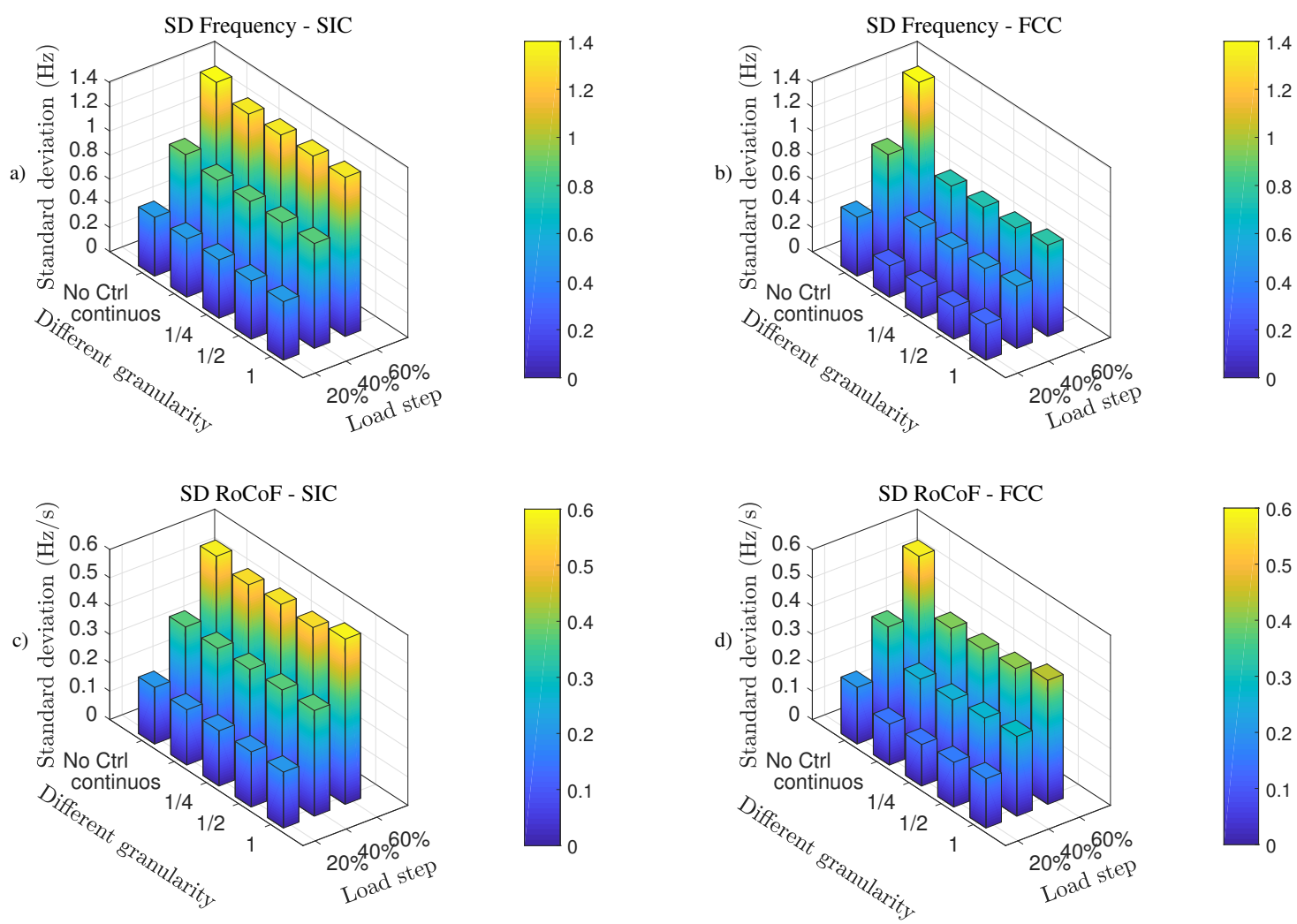

Figure 8: a) SD of the frequency applying SIC and b) SD of the frequency applying FCC, c) SD of the RoCoF applying SIC, d) SD of the RoCoF applying FCC

As expected, Figure 8 shows that in all of the cases the standard deviations depend 
on the size of the load step. On one hand, they are mostly constant for the different considered granularity, on the other hand higher values are found in the uncontrolled cases. Moreover, it is noticeable that beneficial effects on the frequency are found in case of FCC. As presented in Figure 6, the EVs' effect makes the frequency rise to a higher steady-state value. Meanwhile, the SIC controller has an embedded reset logic, which makes the EV set-point go back to $11 \mathrm{~A}$ right after the event. It is of interest to highlight that the FCC shows an unexpected better contribution to the RoCoF limitation in comparison to the SIC. This is due to the limited number of control actions that took place in case of SIC, which is due to the implemented RoCoF deadband (Figure 1-b). Instead, when providing primary regulation via FCC, no deadband is applied, which activates the controller more often, thus contributing more to the RoCoF containment.

This sensitivity analysis shows that, in this islanded microgrid, the granularity does not influence the results. However, one should note that under a certain combination of system attributes (system inertia and stiffness of the power system) and control units (amount of power involved in the regulation, droop, response/ramp time and granularity of the control actions), the granularity might lead to system instability or oscillation between two consequent set-points, as was experienced during the validation phase.

\subsection{Experimental Validation}

Following the results obtained during the simulations, the authors investigate the EVs capability to provide synthetic inertia and frequency containment control in an islanded grid in real circumstances. The experiments are executed in the islanded configuration that is shown in Figure 4, where the diesel is the grid forming unit.

\subsection{Study Case 1}

In the first study case, the frequency variation is triggered by several load steps. A set of load events from the VRB of the same amplitude is applied $(\approx \pm 2 \mathrm{~kW})$, namely, $8.7 \%$ of the initial installed load. To better investigate the controllers as well as the frequency dynamics, an additional set of load events with a different amplitude is applied, specifically 
$(\approx \pm 4 \mathrm{~kW}), 17 \%$ of the initial installed load. The grid units as well as the initial conditions are reported in Table 1 .

The three scenarios are characterised by the same initial conditions and load steps. The first scenario (S1) is a base case, in which the EVs receive a constant current set-point; that is, $11 \mathrm{~A}$ absorbing around $2.5 \mathrm{~kW}$. In the second scenario (S2), the EVs are controlled by the synthetic inertia controller, which modulates the charging level between 6 and $16 \mathrm{~A}$ with steps of $1 \mathrm{~A}$ in function of the RoCoF-current droop characteristic presented in Figure 1 1 b. In the third scenario (S3), the EVs are controlled by the frequency containment controller. The controller modulates the EVs' charging level between 6 and 16 A with steps of $1 \mathrm{~A}$ in function of the frequency-current droop characteristic presented in Figure 1 1 -

The results of the experiments are presented in Figure 9. Figure 9-a shows the system frequency for the three scenarios. Figure 9fb shows the RoCoF measured over $200 \mathrm{~ms}$ in grey and the filtered signal after applying the deadband in red $( \pm 0.8 \mathrm{~Hz} / \mathrm{s}$ deadband is considered). In Figure 9-c the controllers' current setpoint is plotted versus the EVs' absorbed current. Since the three EVs act similarly, only the current of EV1 is presented.

Figure 9-c shows that the EVs change the absorbed current as desired by the different controllers. However, due to the 1 A granularity, the implemented droop and the operating point, the $2 \mathrm{~kW}$ load event implies the FCC to oscillate between 12 and $13 \mathrm{~A}$, and between 9 and $10 \mathrm{~A}$. A $6 \mathrm{~kW}$ load event is only introduced for Scenario 3, at which a stable operating point was found. In fact, Figure 9-c shows that the EV's current did not oscillate for this load event (around $t=450 \mathrm{~s}$ ). However, this oscillation can be reduced by implementing a hysteresis function.

Figure 9-a shows that FCC limits the maximum frequency deviation compared to the base case, while the SIC does not have an effect on it. On the other hand, due to the oscillation between the different set-points in case of FCC, Figure 9 -b shows that the RoCoF was outside the deadband more frequently when compared to scenario 1 and 2 .

Due to the response delay of the EVs and the dynamics of the diesel, which led to a continuous frequency oscillation, it is difficult to perceive a valuable improvement in terms of the RoCoF from SIC. 

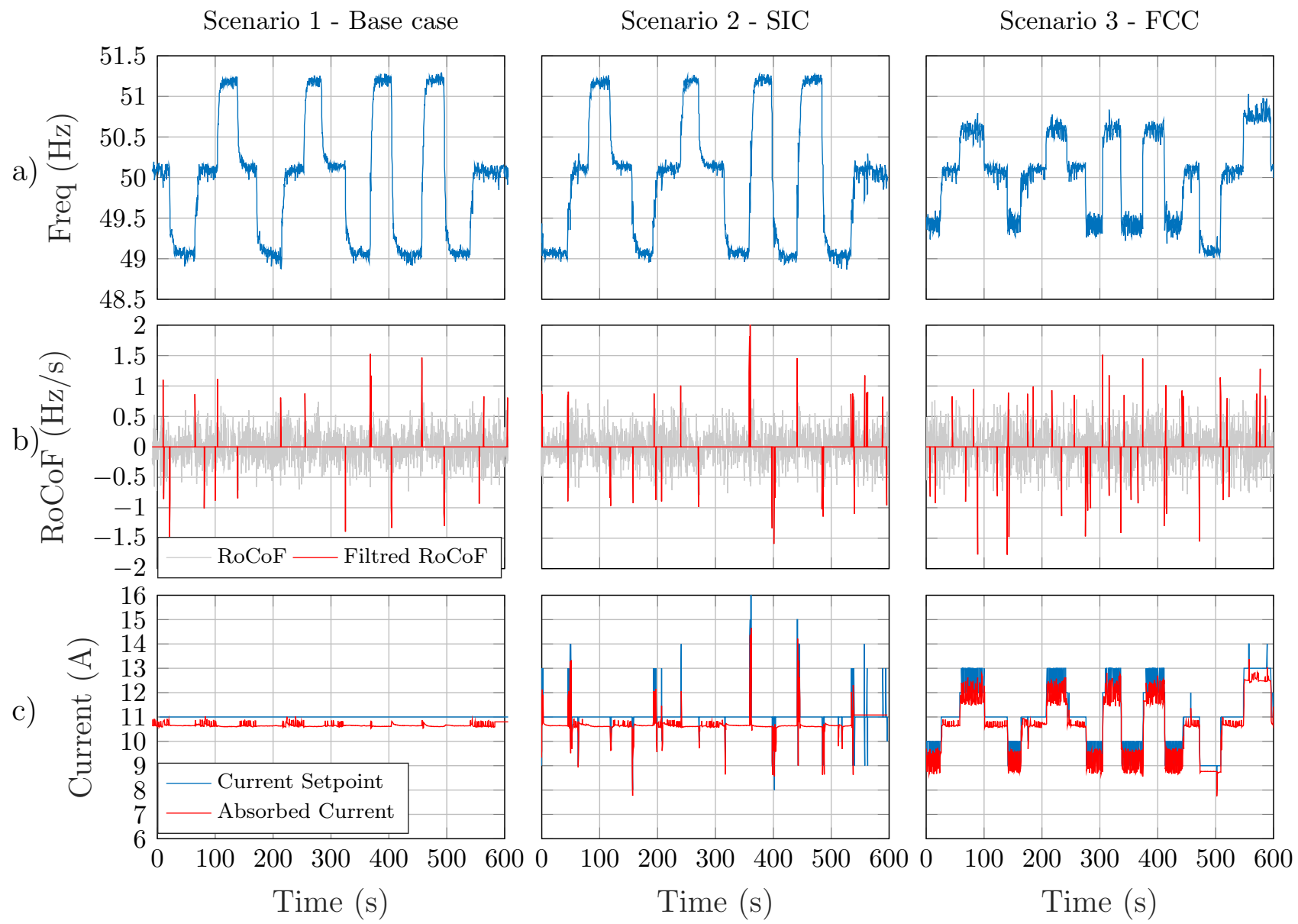

Figure 9: a) Frequency, b) RoCoF, c) EV1's set-point vs absorbed current

To better compare the performance of the two controllers in terms of RoCoF and frequency, the standard deviation and the energy contained in the signal (also addressed as normalised energy) is calculated and presented in Table 3 . For a discrete signal $x(n)$, the normalised energy is calculated as $\frac{1}{N} \sum_{n=1}^{N} x(n)^{2}$, where $N$ is the number of samples taken for computation. It shows that the two controllers do not improve the RoCoF when compared to the base case.

To understand the effects of the SIC on the frequency compared to the base case, Figure 10 shows a zoom of the frequency, the RoCoF and the EV's absorbed current for the three scenarios. In Figure 10-a, one can notice that the SIC has improved the frequency slope as expected and as experienced during the simulations. 
Table 3: SC1 - Standard deviation and normalised energy

\begin{tabular}{|l|l|l|l|}
\hline \multirow{2}{*}{} & \multicolumn{2}{|c|}{ RoCoF } & Frequency \\
\cline { 2 - 4 } & SD & Normalised Energy & SD \\
\hline Base & 0.29 & 0.083 & 0.77 \\
\hline SIC & 0.31 & 0.093 & 0.79 \\
\hline FCC & 0.33 & 0.11 & 0.48 \\
\hline
\end{tabular}

Due to the embedded deadband, the SIC contribution is very limited. However, since the three EVs are characterised by the same delay and granularity (i.e. acting simultaneously with steps), one can observe the sharp change in frequency, which will lead to worse RoCoF compared to the base case as shown in Figure 10-b. To overcome this issue, it might be of interest to study different delays and droops among the EVs. This might induce a more smooth frequency change and, therefore, a better RoCoF. It is of interest to notice from Table 3, where the SD is reported, and Figure 10-b that the FCC has worsened the RoCoF when compared to the SIC and the base case.

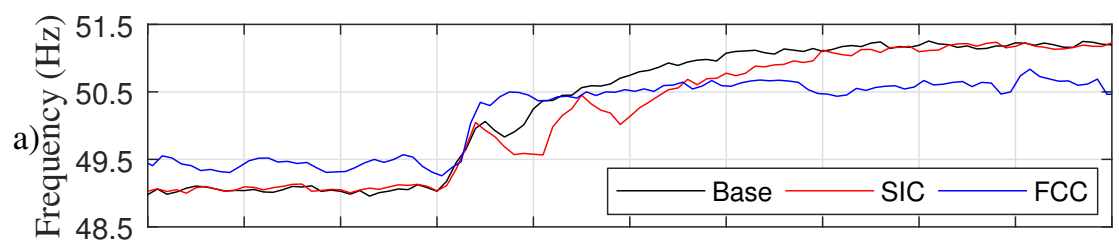

b)

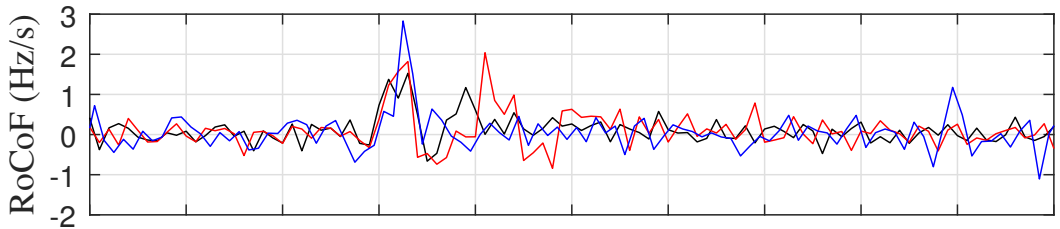

c)

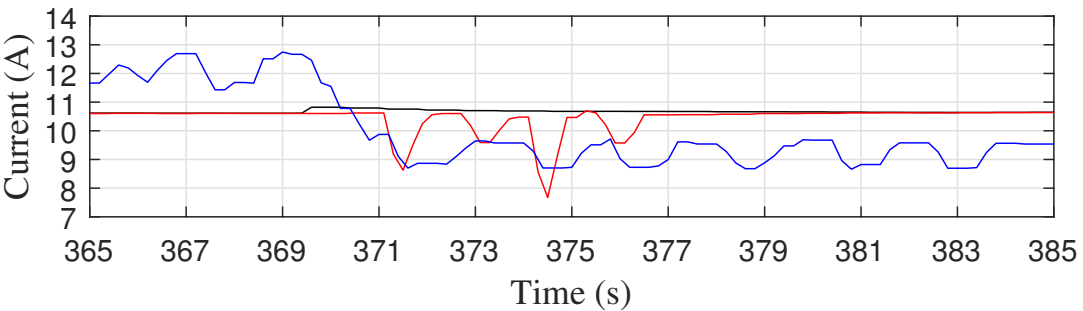

Figure 10: a) Frequency, b) RoCoF, c) EV1's absorbed current 


\subsection{Study Case 2}

In the second study case, the two controllers are analysed during wind power production. The VRB set-point is set to zero during this study case. The same scenarios and droop characteristic as the previous study case are applied. Due to the random stochasticity of the wind generation and the diesel dynamics, the initial and boundary conditions are not exactly identical. Nevertheless, this study case aims to investigate the performance of each controller and the EVs in a more challenging and realistic configuration rather than comparing the different scenarios. The results for SC2 are presented in Figure 11.
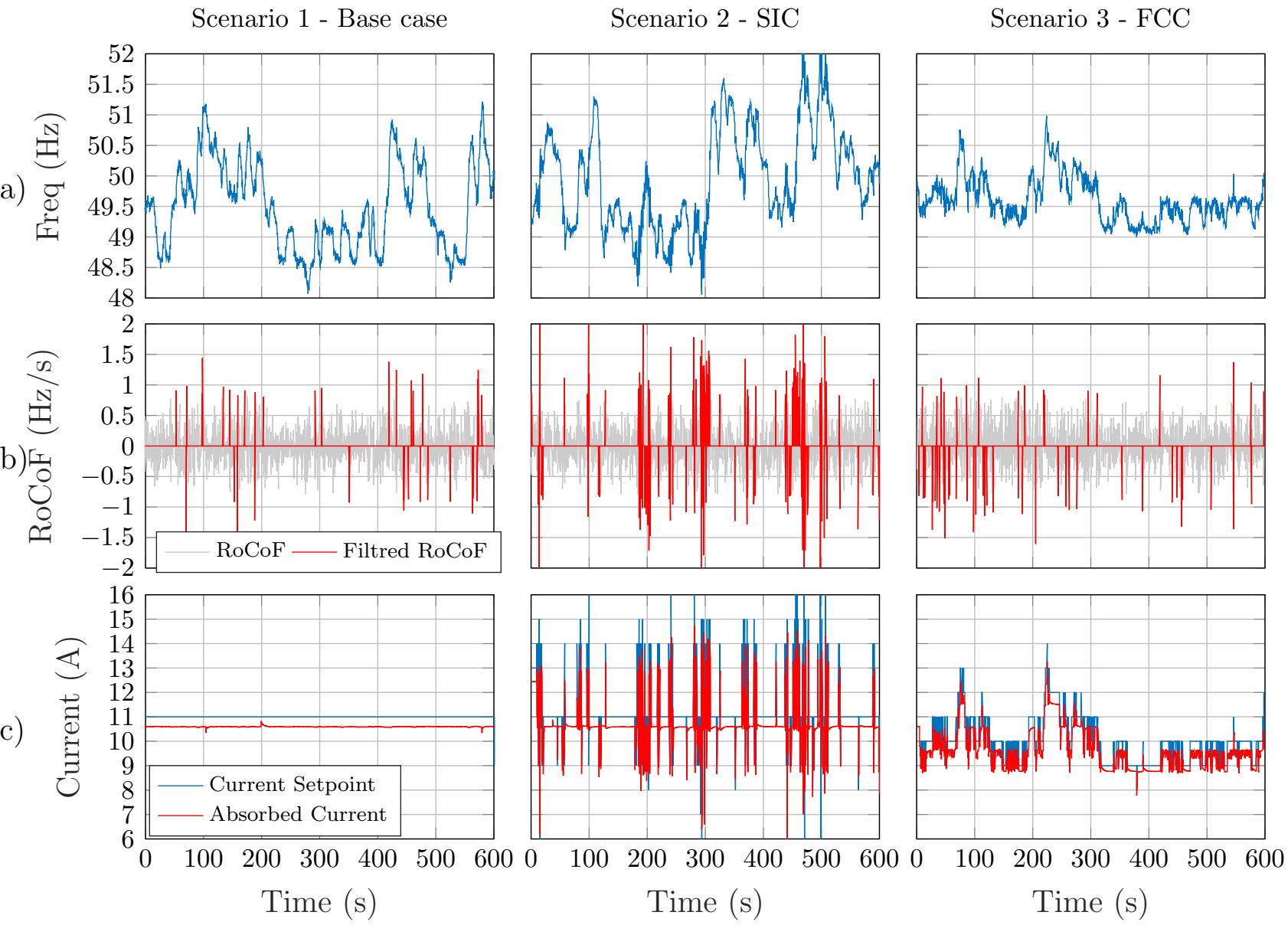

Figure 11: a) Frequency, b) RoCoF, c) EV1's set-point vs absorbed current

Figure 11 - a shows the grid frequency for the three scenarios. Figure 11 tb shows the RoCoF measured over $200 \mathrm{~ms}$ in grey and the filtered signal after applying the deadband 
in red. In Figure 11.c the controllers' current set-point is plotted versus the EVs' absorbed current. Since the three EVs are acting similarly, only the current of EV1 is presented.

The three scenarios were executed over a total time of 30 minutes. The average wind production did not differ so much among the three scenarios: so that the different scenarios are still comparable. Figure 11-a shows that the FCC does have a remarkable effect in limiting the maximum frequency deviation. Figure 11-b shows that by applying the SIC, the RoCoF is outside the deadband more frequently.

To better compare the three scenarios, mean value and standard deviation of the wind production together with the standard deviation of the frequency and the RoCoF are calculated and presented in Table 4.

Table 4: SC2 - Standard deviation and normalised energy

\begin{tabular}{|l|l|l|l|l|l|}
\hline \multirow{2}{*}{} & \multicolumn{2}{|l|}{ Wind Generation } & \multicolumn{2}{|c|}{ RoCoF } & Frequency \\
\cline { 2 - 6 } & Mean & SD & SD & Normalised Energy & SD \\
\hline Base & $3.5 \mathrm{~kW}$ & 1.4 & 0.31 & 0.098 & 0.71 \\
\hline SIC & $4.6 \mathrm{~kW}$ & 1.68 & 0.45 & 0.2 & 0.83 \\
\hline FCC & $3.1 \mathrm{~kW}$ & 1.28 & 0.34 & 0.11 & 0.36 \\
\hline
\end{tabular}

As mentioned previously, due to the random wind production and the non-replicability of the same conditions, the comparison is not perfect, especially in terms of RoCoF due to the continuous variation of the wind profile.

However, the mean value of the wind production among the three scenarios does not differ excessively, which allows the comparison of the standard deviation of the frequency among the scenarios. Table 4 and Figure 11 a show the remarkable positive effect of FCC on the frequency.

\section{Conclusion and Future Work}

Starting from the research question: given the trend of decreasing system inertia, can fast frequency containment compensate or replace the need for synthetic inertia? First, this work analytically showed the interdependence between frequency containment and synthetic 
inertia control on the transient frequency variation and the RoCoF. Second, on the simulation level, it presented the ability of fast frequency control in improving the frequency in terms of nadir, steady state value and RoCoF. It also presented the ability of synthetic inertia control to improve the frequency nadir and slope following an event. While it was acknowledged that EVs could quickly and almost precisely respond to fast changing current set-points, some technical limitations in employing EVs for such services were found. Finally, an experimental validation was conducted, presenting the capabilities and limitations of the two controllers under two different circumstances: following load events in both directions and exogenous wind generation profiles.

Employing the FCC, the simulations results showed a remarkable improvement of the frequency nadir and steady state value. It showed also a very limited improvement in terms of RoCoF. The controller did not limit the maximum RoCoF following the event but it did improve the overall behaviour compared to the base case. Similarly, the experiments showed the ability of FCC in limiting the maximum frequency deviation, both following a series of load events or considering a wind power generation. Although in simulation the sensitivity analysis showed a very limited effect of the granularity, in the experimental phase, due to the 1A granularity, the FCC controller caused the EV absorbed current to oscillate between two consecutive set points, worsening the calculated RoCoF. It should be noted that this oscillation was due the combination of $1 \mathrm{~A}$ granularity, the implemented droop and the operating point. However, this effect can be limited by employing an hysteresis-based algorithm.

By applying the SIC, the simulations presented limited frequency improvements in terms of frequency nadir and frequency slope. They also showed that employing a smaller deadband allowed a better contribution, slightly improving frequency nadir and slope. On the other hand, the smaller deadband worsened the RoCoF trend when compared to the base case. However, in both cases, the controller did not limit the maximum RoCoF value. As mentioned, the SIC slightly improved the frequency slope but worsened the RoCoF. As interpretation of such unexpected phenomena, the authors believe that this might be due to the fact of using the same RoCoF signal for both control and examination purposes. In other 
words, the RoCoF used for control purpose should be calculated over a smaller time window to the one used by the RoCoF relay to detect the variations. Nevertheless, considering the derivative characteristic of the SIC, its implementation might easily lead to frequency oscillation and this limits the ability to exploit the resource (e.g. large deadband). For the SIC, the experiments were conducted for two cases: first, following load events; and second, considering wind power generation. In terms of frequency, the SIC effects were negligible for both cases. For the first case, even if the EVs were able to follow the desired set points, the SIC did not show a noticeable improvement in terms of RoCoF. On the other hand, considering wind power generation, the SIC had very remarkable negative effects in terms of RoCoF. It should be noted that this effect might have been limited by employing less steep droop parameters; on the other hand, this would have limited the EVs participation (i.e. flexibility margin).

In general, employing faster response devices will allow to better exploit the resource's capabilities. For example, this was shown in case of SIC where the smaller time response permitted the use of a narrower deadband. It can be concluded that the actual series produced EVs are able to provide ancillary services in terms of fast frequency response and synthetic inertia by solely relying on unidirectional charging. On the other hand, the experiments show that with the actual EV's response time, a large deadband was needed for the SIC and this limited its contribution. To achieve better performance, new requirements in terms of the EV's response time need to be set. In future work, the authors recognise the importance of extending the analytical formulation of the interdependence of the two controllers on the system frequency. Moreover, it is of interest to expand the analysis over a larger number of flexible units by employing different control attributes.

\section{Acknowledgments}

The work in this paper has been partly supported by the European Commission, under the FP7 project ELECTRA (grant no: 609687) and partly by the Danish research projects Parker (ForskEL kontrakt nr. 2016-1-12410) and Electra Top-up (grant: 3594756936313). 
The authors are also grateful to Nissan Denmark for providing the two Leafs that were used in the experiments.

\section{References}

[1] A. Adrees, P. N. Papadopoulos, J. V. Milanovi, A Framework to Assess the Effect of Reduction in Inertia on System Frequency Response, Power and Energy Society General Meeting (2016) 1-5doi: 10.1109/PESGM. 2016.7741695

[2] A. Ulbig, T. Borsche, G. Andersson, Impact of Low Rotational Inertia on Power System Stability and Operation, in: The 19th World Congress ofthe International Federation of Automatic Control (IFAC14, 2014, pp. 1-12. arXiv:arXiv:1312.6435v2, doi:10.3182/20140824-6-ZA-1003.02615

[3] ENTSO-E, Frequency Stability Evaluation Criteria for the Synchronous Zone of Continental Europe, Tech. rep., ENTSOE (2016).

[4] The Commission for Energy Regulation, Rate of change of frequency modification to the grid code, Tech. rep., CER (2014).

[5] E. Muljadi, V. Gevorgian, M. Singh, S. Santoso, Understanding inertial and frequency response of wind power plants, 2012 IEEE Power Electronics and Machines in Wind Applications (2012) 1-8doi: 10.1109/PEMWA.2012.6316361

[6] S. Sharma, S. H. Huang, N. D. R. Sarma, System inertial frequency response estimation and impact of renewable resources in ERCOT interconnection, IEEE Power and Energy Society General Meeting (2011) 1-6 doi:10.1109/PES.2011.6038993.

[7] R. A. Walling, N. W. Miller, Distributed Generation Islanding Implications on Power System Dynamic Performance, in: Power Engineering Society Summer Meeting,, Chicago, 2002, pp. 92-96. doi:10. 1109/PESS.2002.1043183

[8] C. Ten, P. Crossley, Evaluation of ROCOF relay performances on networks with distributed generation, IET 9th International Conference on Developments in Power Systems Protection (DPSP 2008) 2008 (2008) 522-527. doi:10.1049/cp:20080092

[9] Y. Mu, J. Wu, N. Jenkins, H. Jia, C. Wang, A Spatial-Temporal model for grid impact analysis of plug-in electric vehicles, Applied Energy 114 (February) (2014) 456-465. doi:10.1016/j.apenergy. 2013.10 .006

[10] J. R. Pillai, B. Bak-Jensen, Impacts of electric vehicle loads on power distribution systems, IEEE Vehicle Power and Propulsion Conference, VPPC (2010) 6-11doi:10.1109/VPPC.2010.5729191

[11] A. Foley, B. Tyther, P. Calnan, B. Ó. Gallachóir, Impacts of Electric Vehicle charging under electricity market operations, Applied Energy 101 (2013) 93-102. doi:10.1016/j.apenergy.2012.06.052 
[12] K. Hedegaard, H. Ravn, N. Juul, P. Meibom, Effects of electric vehicles on power systems in Northern Europe, Energy 48 (1) (2012) 356-368. doi:10.1016/j.energy.2012.06.012.

[13] M. H. Amini, M. Parsa, O. Karabasoglu, Simultaneous allocation of electric vehicles ' parking lots and distributed renewable resources in smart power distribution networks, Sustainable Cities and Society 28 (2017) 332-342. doi:10.1016/j.scs.2016.10.006.

[14] M. H. Amini, M. P. Moghaddam, Probabilistic Modelling of Electric Vehicles ' Parking Lots Charging Demand, in: Electrical Engineering (ICEE), 2013 21st Iranian Conference, 2013, pp. 3-6. doi:10. 1109/IranianCEE. 2013.6599716.

[15] A. Molina-garcía, F. Bouffard, D. S. Kirschen, Decentralized Demand-Side Contribution to Primary Frequency Control, IEEE Transactions on Power Systems 26 (1) (2011) 411-419. doi:10.1109/TPWRS . 2010.2048223.

[16] M. R. V. Moghadam, S. Member, R. T. B. Ma, Distributed Frequency Control in Smart Grids via Randomized Demand Response, IEEE Transactions on Smart Grid 5 (6) (2014) 2798-2809.

[17] W. Kempton, J. Tomić, Vehicle-to-grid power implementation: From stabilizing the grid to supporting large-scale renewable energy, Journal of Power Sources 144 (1) (2005) 280-294. doi:10.1016/j. jpowsour.2004.12.022

[18] E. Sortomme, M. A. El-sharkawi, Optimal Scheduling of Vehicle-to-Grid Energy and Ancillary Services, IEEE Transactions on Smart Grid 3 (1) (2012) 351-359. doi:10.1109/TSG.2011.2164099.

[19] D. Wang, J. Coignard, T. Zeng, C. Zhang, S. Saxena, Quantifying electric vehicle battery degradation from driving vs . vehicle-to-grid services, Journal of Power Sources 332 (2016) 193-203. doi:10.1016/ j.jpowsour.2016.09.116

[20] K. Knezović, C. Træholt, M. Marinelli, P. B. Andersen, Active integration of electric vehicles in the distribution network theory, modelling and practice, Phd thesis, Technical University of Denmark (2017).

URL http://orbit.dtu.dk/files/131995291/Knezovic\{_\}PhDthesis\{_\}final.pdf

[21] Y. Mu, J. Wu, J. Ekanayake, N. Jenkins, H. Jia, Primary frequency response from electric vehicles in the Great Britain power system, IEEE Transactions on Smart Grid 4 (2) (2013) 1142-1150. doi: 10.1109/TSG.2012.2220867.

[22] K. Knezović, S. Martinenas, P. B. Andersen, A. Zecchino, M. Marinelli, Enhancing the Role of Electric Vehicles in the Power Grid: Field Validation of Multiple Ancillary Services, IEEE Transactions on Transportation Electrification 7782 (c) (2016) 1-1. doi:10.1109/TTE.2016.2616864.

[23] W. Kempton, J. Tomic, Vehicle-to-grid power implementation: From stabilizing the grid to supporting large-scale renewable energy, Journal of Power Sources 144 (1) (2005) 280-294. doi:10.1016/j. jpowsour.2004.12.022 
[24] F. Teng, Y. Mu, H. Jia, J. Wu, P. Zeng, G. Strbac, Challenges on primary frequency control and potential solution from EVs in the future GB electricity system, Applied Energy 194 (2016) 353-362. doi:10.1016/j.apenergy.2016.05.123

[25] A. Schuller, C. M. Flath, S. Gottwalt, Quantifying load flexibility of electric vehicles for renewable energy integration, Applied Energy 151 (2015) 335-344. doi:10.1016/j.apenergy.2015.04.004.

[26] P. Tielens, D. V. Hertem, The relevance of inertia in power systems, Renewable and Sustainable Energy Reviews 55 (2016) 999-1009. doi:10.1016/j.rser.2015.11.016.

[27] IEC 61851-1:2010, Electric vehicle conductive charging system Part 1: General requirements (2010).

[28] M. Marinelli, S. Martinenas, K. Knezović, P. B. Andersen, Validating a centralized approach to primary frequency control with series-produced electric vehicles, Advances in Life Course Research 7 (2016) 6373. doi:10.1016/j.est.2016.05.008

[29] J. A. Suul, S. D. Arco, G. Guidi, Virtual Synchronous Machine-Based Control of a Single-Phase BiDirectional Battery Charger for Providing Vehicle-to-Grid Services, IEEE Transactions on Industry Applications 52 (4) (2016) 3234-3244. doi:10.1109/TIA.2016.2550588.

[30] L. Martini, A. Morch, L. Radaelli, C. Caerts, C. Tornelli, S. Hänninen, H. Brunner, Electra IRP approch to voltage and frequency control for future power systems with high DER penetration, in: 23rd International Conference on Electricity Distribution CIRED, 2015, pp. 1-5.

[31] ENTSO-E, ENTSO-E, Continental Europe Operation Handbook, Tech. Rep. Cc, ENTSOE (2009).

[32] P. Kundur, J. Paserba, V. Ajjarapu, G. Andersson, A. Bose, C. Canizares, N. Hatziargyriou, D. Hill, A. Stankovic, C. Taylor, T. Van Cutsem, V. Vittal, Definition and Classification of Power System Stability, IEEE Transactions on Power Systems 21 (3) (2004) 1387-1401. doi:10.1109/TPWR. 2004. 825981 .

[33] P. Kundur, Power System Stability and Control, McGraw-Hill, 1994.

[34] A. Zecchino, M. Rezkalla, M. Marinelli, Grid Support by Single-Phase Connected Electric Vehicles without V2G Capability : Fast Primary Frequency Control, in: International Universities' Power Engineering Conference - UPEC, Coimbra, 2016, p. 6.

[35] M. Rezkalla, S. Martinenas, A. Zecchino, M. Marinelli, Implementation and Validation of Synthetic Inertia Support Employing Series Produced Electric Vehicles, in: International Conference on Electricity Distribution - CIRED, 2017, pp. 12-15, accepted for publication.

[36] M. Rezkalla, M. Marinelli, M. Pertl, K. Heussen, Trade-off analysis of virtual inertia and fast primary frequency control during frequency transients in a converter dominated network, in: 2016 IEEE Innovative Smart Grid Technologies - Asia (ISGT-Asia), 2016, pp. 890-895. doi:10.1109/ISGT-Asia. 2016.7796503 . 